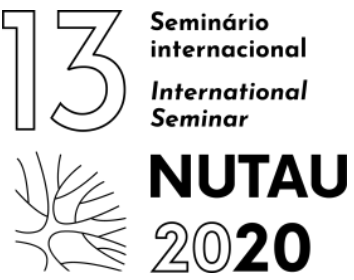

\title{
Poda e manejo de vegetação urbana: oportunidades de projeto
}

\author{
Paulo Cesar Machado Ferroli ${ }^{1}$, Lisiane Ilha Librelotto ${ }^{2}$, Ialê Ziegler Libanio da Silva ${ }^{3}$, Natália Geraldo ${ }^{4}$ \\ ${ }^{1}$ UFSC - DEGR, Virtuhab, Dr., pcferroli@gmail.com \\ 2 UFSC, Pos-ARQ, Virtuhab, Dra. Lisiane.librelotto@gmail.com \\ 3 UFSC, Arquitetura e Urbanismo, Graduanda, Virtuhab, ialezieglerr@gmail.com \\ ${ }^{4}$ UFSC, Arquitetura e Urbanismo, Graduanda, Virtuhab, natalia.vgeraldo@gmail.com
}

\begin{abstract}
RESUMO: Apesar de todo avanço tecnológico o ser humano ainda não é capaz de evitar problemas ambientais decorrentes de ventos fortes, como tornados e ciclones. Com efeitos bastante destrutivos, esses fenômenos climáticos são responsáveis por prejuízos materiais e humanos em todo planeta. A poda de árvores, se bem realizada, pode ajudar a prevenir efeitos danosos em casos de temporal, como quedas de galhos e até árvores inteiras. Os resíduos provenientes destas podas, ou quedas, pode ser usado para compor produtos de design, uma melhor alternativa do que a destinação para aterros ou mesmo a queima sob a forma de lenha, que restitui o carbono armazenado para a atmosfera. Esse artigo mostra alguns exemplos práticos de aproveitamento de resíduos arbóreos em projetos de produtos.
\end{abstract}

PALAVRAS-CHAVE: Resíduos, materiais, sustentabilidade, design

\begin{abstract}
Despite all technological advances, human beings are still unable to avoid environmental problems resulting from strong winds, such as tornadoes and cyclones. Causing serious destructive effects, these climatic phenomena are responsible for material and human damage across the planet. Pruning trees, if done well, may help prevent harmful effects in cases of thunderstorms, such as falling branches and even whole trees. These pruning excesses and residues from falls can be used to compose design products, which are a better alternative than landfilled the wood or even burning it as firewood, restoring the stored carbon to the atmosphere. This article shows some practical examples of using tree residues in design projects.
\end{abstract}

KEYWORDS: Waste, materials, sustainability, design

\section{INTRODUÇÃO}

A sustentabilidade está diretamente relacionada a multidisciplinariedade. Em essência, seu pleno entendimento resgata o conceito generalista da "ciência de antigamente", quando os grandes filósofos, eram também matemáticos, músicos, artesãos, dominavam arquitetura, escreviam leis, e assim por diante. Ao estudarmos a história passamos a compreender plenamente os fenômenos que levaram a necessidade da especialização do conhecimento, visto ser humanamente impossível o domínio de distintas e às vezes até conflitantes áreas do saber, mesmo que, muitas vezes, estas possuíssem elementos de auto complementação.

Desse modo os curandeiros viram seu conhecimento ser dividido entre medicina, odontologia, farmácia, etc. E posteriormente os médicos viram novamente seu conhecimento de clínica geral ser fragmentado em campos diversos de especialização. $\mathrm{Na}$ área técnica e projetual, as engenharias ramificaram-se em uma grande quantidade de especificidades, de tal modo que, mesmo que em essência um engenheiro entenda o ramo de outro, os conselhos profissionais (CONFEA e CREAs) criaram uma série de leis que regulamentam a atuação profissional de acordo com a área de formação do engenheiro e reservam fatias do mercado para a atuação de profissionais especializados. E isso acontece em todas as áreas. A medicina e engenharia, citadas aqui, são apenas exemplos da fragmentação e especialização do conhecimento

Esta fragmentação traz vantagens e desvantagens, existindo também a necessidade de profissionais mais generalistas. Em certos casos, a especialização é fundamental. O sucesso de uma ponte de safena depende de conhecimento altamente especializado. Contudo, em muitas vezes, o ser humano parece ter esquecido de que, a fragmentação do conhecimento generalista em subáreas coexiste com um intenso
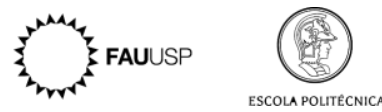
trabalho colaborativo. Quando se divide o todo em partes, as partes tornam-se maiores que o todo.

Então parece óbvio que, a especialização não destitua o conhecimento de base e generalista, o qual irá permitir tanto a discussão entre pares especializados, quanto a discussão generalizada para que se possa compreender a problemática de forma integral e coesa.

A sustentabilidade, enquanto ciência complexa, tende a resgatar a importância do conhecimento generalista, da mesma forma que integra conhecimento disciplinares, visto que não pode ser separada por eixos imaginários de conhecimento, onde necessariamente cada vertente (econômica, social ou ambiental) tem seu limite. Ou seja, não se trata de um profissional tentando resolver um problema de forma generalista, mas da integração de vários profissionais, ainda que especialistas em suas áreas, colocando suas diferentes visões na resolução do mesmo problema.

Entender o ciclo biológico das árvores é um ramo da biologia. Também pertence a agronomia seu cultivo e manejo assim como é uma especialidade da engenharia florestal. Em ambientes urbanos, tais ciclos envolvem a engenharia ambiental na disposição e coleta destes resíduos, tanto quanto o planejamento urbano, com a participação de arquitetos, urbanistas e paisagistas além de diversas modalidades de engenharia (de tráfego, civil, de saneamento e assim por diante).

A atividade projetual (que neste artigo aborda design de produto, arquitetura e engenharia) está em constante modificação. $O$ que se entende por projeto está no DNA humano. Constantemente estamos "projetando", quer seja um produto, um serviço, uma ação. Ao longo dos anos, a qualidade surgiu como o elo que uniria todos os aspectos relevantes a um projeto, definindo-se que, em essência, um projeto de qualidade, por si só, estaria garantindo a satisfação do usuário. Contudo, a qualidade está diretamente relacionada ao desejo da melhoria contínua, onde as necessidades vão se alterando, modificando e ampliando. O que era considerado confortável em 1970 parece hoje quase impossível de usar. O que era considerado belo nos anos 1990 não necessariamente é considerado belo nos dias de hoje. E assim por diante.

$O$ reuso de partes das árvores, provenientes da poda ou da queda desastrosa, faz parte desta ciência complexa, que envolve a atuação conjunta de diversos profissionais. Desta forma pode-se entender as espécies envolvidas, melhores locais de implementação da vegetação urbana e espécies mais adequadas de forma a valorizar a paisagem, promoção de biomas locais, não danificar estruturas viárias e patrimônio, assim como determinação de procedimentos de inspeção, avaliação, manutenção, poda e remoção de resíduos.

Em muitas cidades a poda de árvores urbanas, a exemplo de Florianópolis, pode ser solicitada a prefeitura e o manejo autorizado pela FLORAM. Em outros municípios de Santa Catarina, por exemplo Governador Celso Ramos, a prefeitura responsabiliza donos de imóveis pela manutenção da vegetação em vias públicas e penaliza (o que parece bastante contraditório em termos de ecologia) a implementação destas em vias públicas.

Ainda em Santa Catarina, como vislumbre da problemática, a passagem do ciclone bomba, em 30 de junho, atingiu mais de 100 cidades, causou nove mortes, e queda de energia elétrica em diversos domicílios. Muitos dos estragos foram decorrentes da queda de vegetação urbana e causaram milhões em prejuízos aos cofres públicos, além do dano ambiental. (NSC, 2020). Na ocorrência, os ventos de até 134 $\mathrm{km} /$ hora em Florianópolis, derrubaram árvores sobre casas, rede elétrica, automóveis e vias públicas. As quedas ocorreram durante os 3 dias de ciclone e permaneceram ocorrendo até um mês após a incidência principal, onde só neste período foram contabilizadas mais de 300 árvores derrubadas.

O estado da arte na área evidencia o amplo uso destes resíduos na compostagem, adubação e produção de mudas (MANGUEIRA, GOMES E SOUSA, 2019; SEMMA, 2018). A Prefeitura de Florianópolis, desde 2012 possui um projeto de destinação para estes resíduos, que inclui a trituração, compostagem e adubação (PMF, 2012). Os resíduos da vegetação, entretanto, possuem grande valor, sobretudo para o design e engenharia em projetos de alto valor agregado em ecodesign.

A definição de projeto sustentável mudou ao longo dos anos. Por exemplo, sob a perspectiva inicial do ecodesign, que foi definido por Manzini e Vezzoli (2002) como a atividade que liga o tecnicamente possível com o ecologicamente necessário - e que com isso, favorece o surgimento de novas propostas social e culturalmente aceitáveis - as etapas iniciais do projeto do produto referem-se ao desenvolvimento de um novo conceito, a organização do projeto piloto e a seleção de materiais. Essa definição é moderna, e já traz implícita as modificações conceituais do que se entende por sustentabilidade resultantes principalmente das conferências mundiais de 1972 e 1992.

Com o passar dos anos percebe-se que o ecodesign foi acrescido, diante da realidade encontrada, para a plenitude do conceito, pelo menos da tríade moderna da sustentabilidade, com os eixos econômico, social e ambiental sendo considerados de forma integrada (modelo ESA - LIBRELOTTO, 2009). Claramente que resultante da Rio+10, entre outras, conceitualmente essa modificação é fundamental, pois com isso insere- 
se na atividade de projeto perspectivas mais subjetivas a medida que incorporam-se às demandas socioculturais.

Se tradicionalmente os projetos envolvendo as engenharias possuem mais evidência nos aspectos quantitativos, tradicionais nas considerações técnicas e econômicas, enquanto que na arquitetura e design os aspectos estético-sensoriais recebem prioridade, também é verdade que a formação básica destes profissionais está se modificando, favorecendo o entendimento mútuo da área de saber de cada um. $E$ isso devido a sustentabilidade, que contribuiu para uma abordagem interdisciplinar, onde todos estes aspectos devem estar equilibrados na linguagem projetual de designers, arquitetos e engenheiros. Soma-se a isso os conceitos recentes de eco inovação, economia circular e pensamento sistêmico, modelagem simultânea integrada e manufatura aditiva, originados das pesquisas dos últimos anos.

O presente artigo tem como objetivo mostrar, dentro da realidade comentada nos parágrafos anteriores, exemplos de projetos aproveitando-se de resíduos arbóreos, provenientes de desastres naturais ou podas planejadas. A temática foi escolhida no sentido de buscar relacionar os aspectos da sustentabilidade em casos específicos, estilo estudo de caso.

\section{PROCEDIMENTOS METODOLÓGICOS E REVISÃO BIBLIOGRÁFICA}

Para o desenvolvimento deste artigo, utilizou-se a pesquisa exploratória-descritiva, com aplicação do procedimento de pesquisa bibliográfica, documental e pesquisa de campo, incluindo fotografias, análises in loco, projeto e experimentação. A coleta de dados de ordem prática foi realizada no próprio local onde aconteceram as podas e os desastres ambientais.

A temática de projetos e experiências de valorização dos resíduos arbóreos urbanos é interessante porque oportuniza uma relação entre diversas áreas e profissionais. É possível encontrar designers, arquitetos, engenheiros, artistas plásticos, biólogos, técnicos e artesãos de diferentes níveis e formação e até mesmo pessoas que não estão diretamente ligados à área projetual buscando transformar os resíduos em móveis de jardim, mobiliário condominial, residencial e urbano.

A figura 1 mostra um exemplo encontrado em Alves (2016), que comenta sobre como as árvores caídas na cidade de São Paulo estão sendo transformadas em mobiliário urbano. A proposta da prefeitura de São Paulo, através do Programa Municipal Mobiliário Ecológico tem o exemplo mostrado assinado pelo designer Hugo França, especialista em esculturas e mobílias de madeira. $\mathrm{O}$ objetivo do projeto é reaproveitar os resíduos provenientes de árvores que caíram, transformando o material lenhoso, que normalmente seria queimado em lenha ou mesmo deixado a deriva em lixões, em mobiliários urbanos (bancos) para áreas públicas.

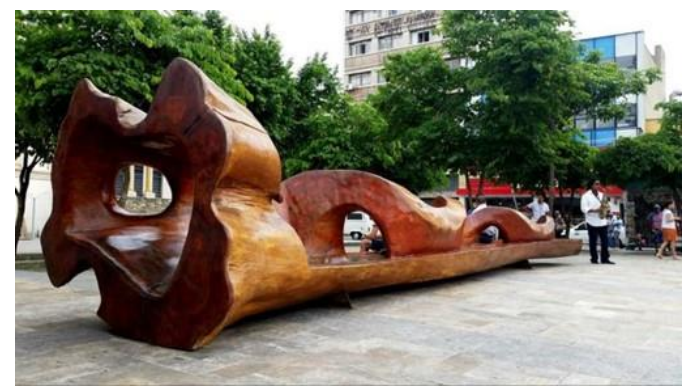

Figura 1: Mobiliário urbano proveniente de árvore caída. Fonte: Alves, 2016.

Outros exemplos aparecem em Rosa (2018), conforme mostra a figura 2. De acordo com o encontrado em https://ciclovivo.com.br a ideia é produzir móveis rústicos restaurando madeira de árvores que caíram naturalmente. Destaca-se nesse aspecto a tendência atual de valorização do minimalismo e uso de materiais sustentáveis na decoração da casa, com móveis de madeira, ao invés de metais e plásticos.

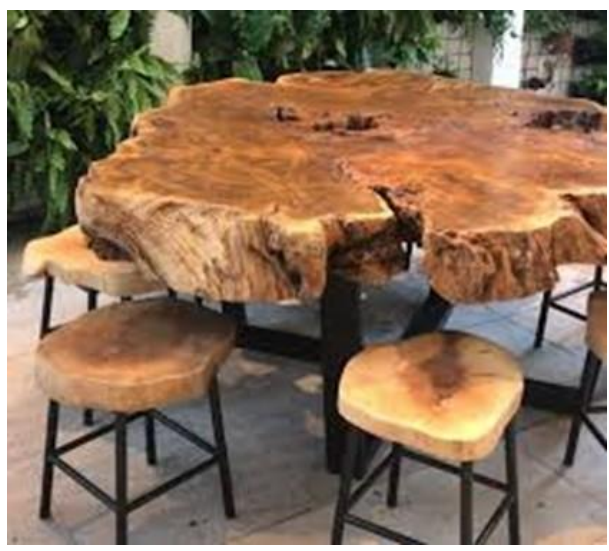

Figura 2: Mobiliário residencial proveniente de árvore caída. Fonte: Ciclo vivo (2020)

Em função da limitação de espaço, não é possível o aprofundamento em exemplos e estudos de caso. Uma busca na internet proporciona uma quantidade muito grande de projetos, tanto em mobiliário urbano quanto residencial. Alguns destes projetos foram usados como referências estético-formais nos projetos que serão apresentados na sequência.

\section{POSSIBILIDADE DE REUSO DAS PARTES DAS ÁRVORES}

\subsection{Raízes, galhos e folhas}

A figura 3 mostra um exemplo de raízes decorativas, encontrada em um restaurante na $B R$ 101, município de Joinville, SC. 


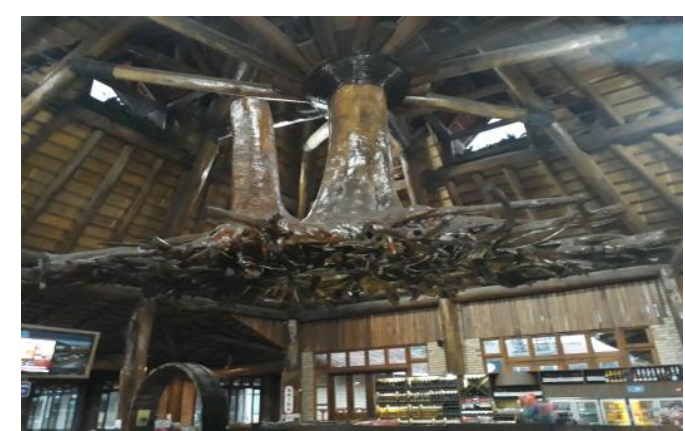

Figura 3 - Raízes decorativas. Fonte dos autores.

Já na figura 4, o artista Horácio Moretto visitava agrícolas da região de Lençóis (SP) e recuperava as raízes das árvores que porventura tivessem caído recentemente. Diferente da figura anterior, em que a raiz foi aproveitada como um todo, nesse exemplo temos a utilização parcial dessa estrutura natural para a criação de esculturas e artefatos de decoração.

Em sua maioria, são raízes das espécies gabiroba, araçá, café ou goiabeira, cujas formas possibilitam a usinagem, tratamento e transformação em figuras animais, humanas ou folclóricas. Os colecionadores das obras ressaltam que cada escultura mantém a forma como foi encontrada na natureza, contando com poucas alterações, como suavização das pontas, limpeza e o uso do verniz para fins de conservação.

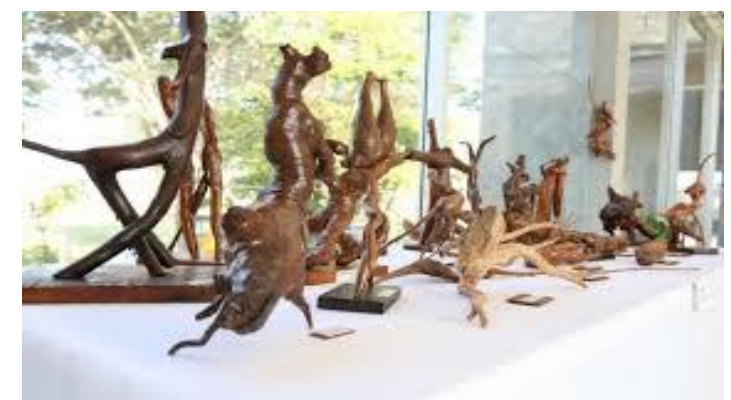

Figura 4 - Obras do Artista Horácio Moretto. Fonte: Revista o comércio 2018.

As figuras 5 e 6 mostram outros exemplos de aproveitamento de galhos e folhas.

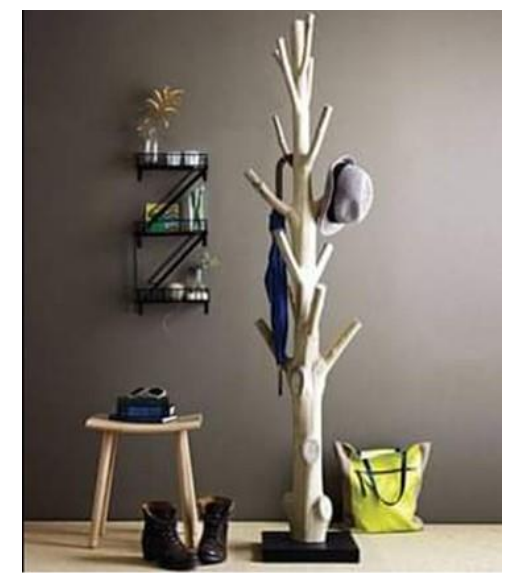

Figura 5 - Cabide de árvore. Fonte: BERTRAND, 2014.

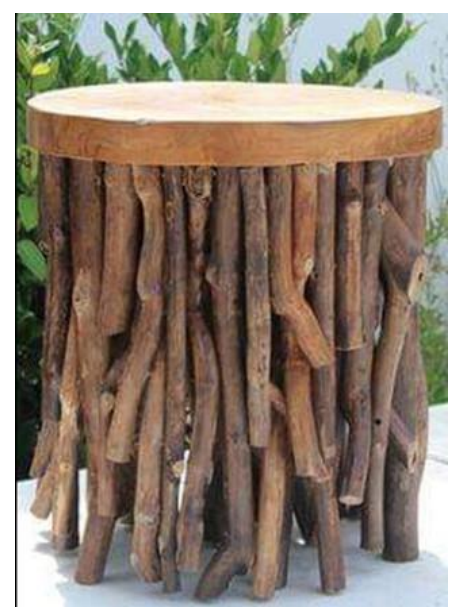

Figura 6 - Banquinho feito com galhos. Fonte: STYLOWI, 2020

\subsection{Tronco}

É a parte mais explorada quando fala-se de reaproveitamento arbóreo após queda por desastres naturais. Poucas pesquisas são necessárias para que apareçam milhares de referências de mobiliário utilizando tal parcela da árvore. Além de oferecerem uma estética única, possuem alta durabilidade e tamanho favorável à adaptação criativa pelo usuário. As figuras 7 e 8 são exemplos da variabilidade de seu uso.

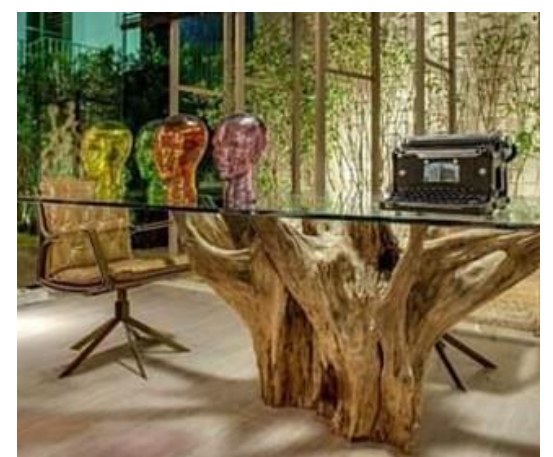

Figura 7 - Mesa “Raiz". Fonte: Decora Lovers, 2014.

Em exposição no espaço "Living da Imprensa" da Casa Cor 2014, a arquiteta Carla Arigón Felippi trouxe este aparador desenvolvido por Juliano Guidi, designer. Embora o nome da obra se refira à raiz da planta, a mesa utiliza o tronco de Imbuia para sua sustentação. A árvore, de origem brasileira e considerada de alta qualidade principalmente por sua longevidade, foi tratada e transformada em parte do móvel após sua queda em uma das fazendas da família do designer, no Paraná.

Juliano explica que cada peça pode demorar até dois anos para ser concluída, pois o resgate do resíduo arbóreo muitas vezes é demorado. Por se tratar de uma queda natural, a árvore pode estar parcialmente enterrada ou até submersa quando encontrada. 


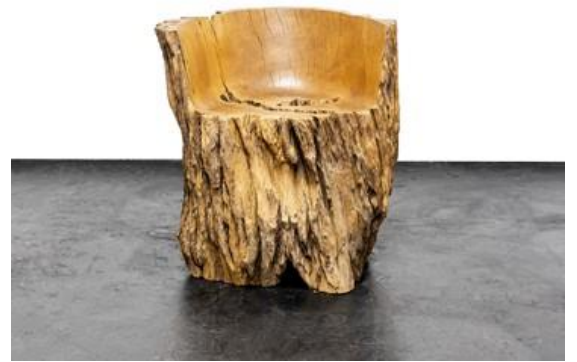

Figura 8 -Cadeira Abaquar. Fonte: Hugo França, 2020.

\section{PROJETOS}

\subsection{Aroeira-vermelha}

A figura 9 mostra uma árvore da espécie Aroeiravermelha (Schinus terebinthifolius), que caiu durante uma tempestade na cidade de Florianópolis, SC, durante o mês de Agosto de 2020. De acordo com Neves e outros (2016), a Aroeira-vermelha é uma espécie perenifólia que, quando jovem, apresenta de $5 \mathrm{~m}$ a $10 \mathrm{~m}$ de altura e diâmetro entre $20 \mathrm{~cm}$ e $30 \mathrm{~cm}$. Os indivíduos adultos chegam a alcançar $15 \mathrm{~m}$ de altura e $60 \mathrm{~cm}$ de diâmetro de tronco. Apresenta tronco geralmente tortuoso, curto, de copa larga, arredondada e pouco densa. A casca externa do tronco é escura, grossa e rugosa, áspera, sulcada e escamosa, que se desprende em placas irregulares.

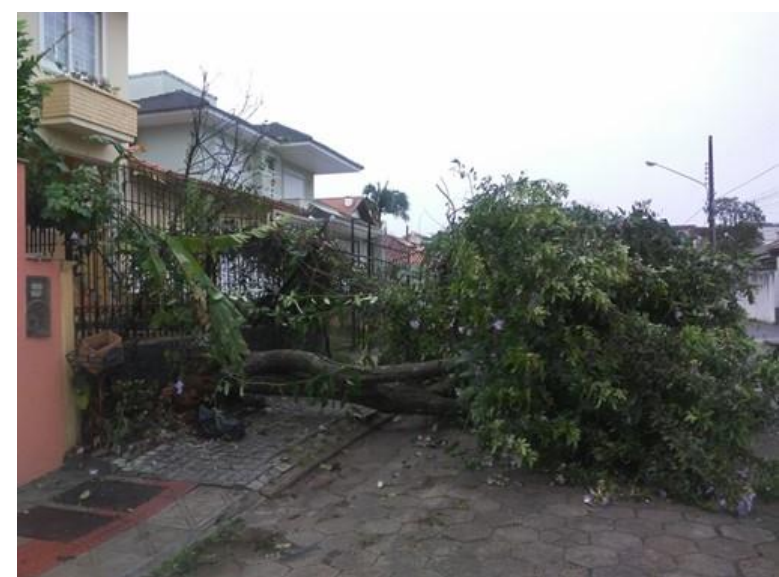

Figura 9: Queda de Aroeira-vermelha por temporal em Florianópolis (SC), Agosto de 2020. Fonte: própria.

A aroeira-vermelha ocorre de forma natural no Leste e Nordeste da Argentina, no Leste do Paraguai, no Uruguai e nos estados brasileiros de Sergipe, Paraíba, Alagoas, Pernambuco, Rio Grande do Norte, Bahia, Espirito Santo, Mato Grosso do Sul, Minas Gerais, Paraná, Rio de Janeiro, Rio Grande do Norte, Santa Catarina e São Paulo (Gomes e outros, 2013). Em 1898 foi introduzida como planta ornamental na Flórida, Sul dos Estados Unidos, onde tornou-se espécie exótica invasora e, posteriormente, em vários países da Europa e América do Sul.

Inicialmente buscou-se qual seria a melhor solução ao problema, visto ser uma árvore de grande porte que estava na rua, prejudicando o trânsito local. Dentre as várias opções, a que pareceu melhor foi procurar aproveitar todo o possível em projetos de móveis rústicos, galhos para lenha e as folhas foram enviadas para a FLORAM (Fundação Municipal do Meio Ambiente de Florianópolis).

A figura 10 mostra um dos projetos que foi realizado com a árvore. Foi aproveitado um tampo de granito antigo para compor o projeto de um banco. Dois pedaços de troncos grandes foram usinados de modo a proporcionar o encaixe do tampo de granito. Cunhas de madeira foram inseridas de modo que o sistema ficasse seguro, sem trepidações e sem risco de tombamento. Dois pedaços menores do troco foram cortados para servirem de apoio.

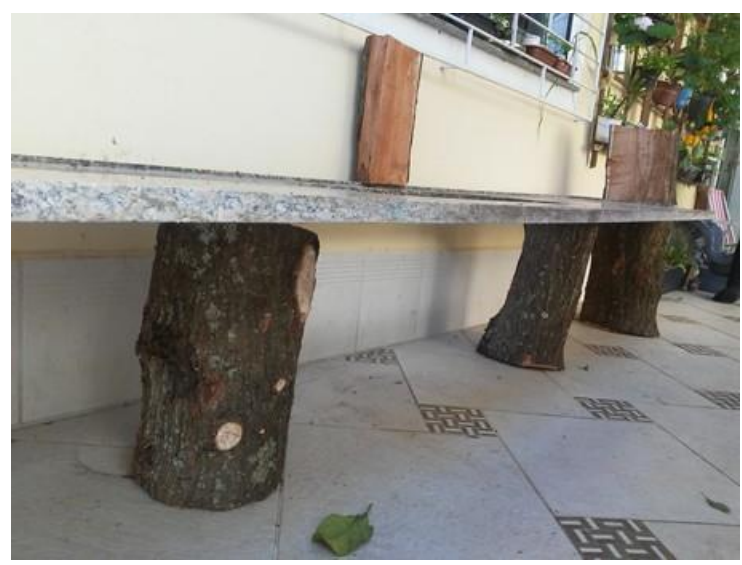

Figura 10: Banco já montado. Fonte: própria.

Os demais pedaços da árvore foram também aproveitados em outros projetos, que por limitação de espaço não serão mostrados aqui. Em um deles, o tronco principal foi cortado de modo a compor uma mesa de centro, com vidro; em outro, pedaços do tronco formaram um móvel pra vasos (figura 11).

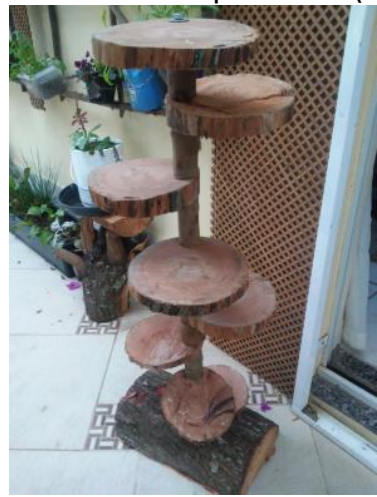

Figura 11: Móvel para vasos de plantas. Fonte: própria.

\subsection{Projeto - Boldo-Alumã}

Diferente do anterior, esse exemplo trata de aproveitamento em caso de poda. Segundo Araujo e Araujo (2016) a poda é uma das práticas mais importantes na manutenção de árvores urbanas. Quando bem conduzida, pode reduzir possíveis danos 
causados por vento, por ataques de insetos, problemas de doenças e melhorar a arquitetura da copa.

A figura 12 mostra a árvore onde foi realizada a poda, que de acordo com o encontrado em https://hortodidatico.ufsc.br/boldo-aluma/ trata-se do Boldo-Alumã (Gymnanthemum amygdalinum), um arbusto grande, pouco ramificado, de ramos quebradiços, com altura variando de 2 a 4 metros. Suas folhas são simples, inteiras, membranáceas, com 5 a $12 \mathrm{~cm}$ de comprimento e sabor amargo.

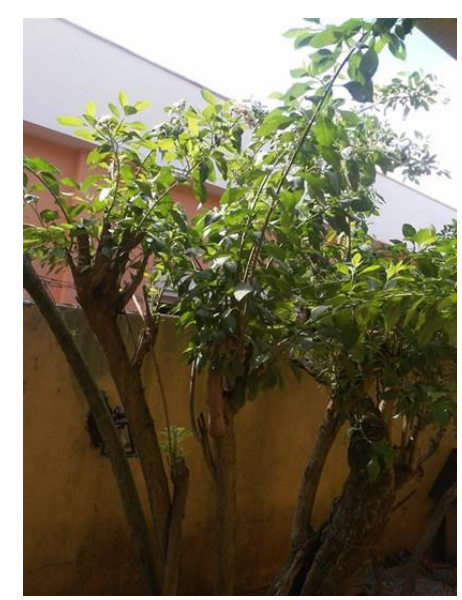

Figura 12: Boldo-alumã depois da poda. Fonte: própria.

A figura 13 mostra o resultado pronto do projeto. Inicialmente os galhos foram cortados, pregados e depois amarrados com cordas de sisal para dar sustentação e efeito estético. O conjunto foi então preso à parede por meio de parafusos e buchas. Os vasos são presos por arames de aços galvanizado.

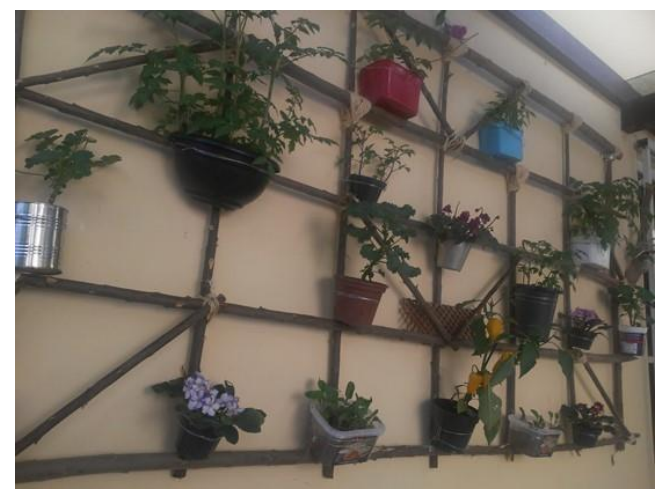

Figura 13: Projeto finalizado. Fonte: própria.

Os galhos menores foram usados em outro projeto, na construção de uma mesinha de centro. Para o tampo foi usado um pedaço de chapa de MDF que estava sem uso e iria para o lixo. O resultado final é mostrado na figura 14 .

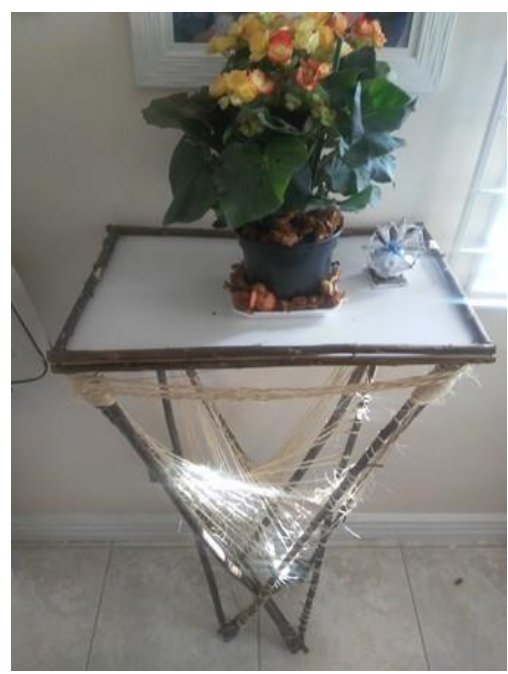

Figura 14: Projeto final. Fonte: própria.

\section{CONCLUSÃO}

Este artigo teve por objetivo mostrar usos alternativos que se pode dar a resíduos arbóreos provenientes de desastres ou podas. De acordo com dados fornecidos pela Prefeitura de Florianópolis (http://www.pmf.sc.gov.br), somente no último ciclone que passou pela cidade na terça-feira, 30 de junho de 2020, 300 árvores tombaram. A maioria acaba em aterros, ou é aproveitada como lenha.

Utilizar-se portanto destes resíduos para compor produtos de design é uma alternativa interessante visando o aproveitamento do material, reduzindo material no lixo e sendo uma alternativa de uso no lugar de produtos plásticos ou semelhantes.

\section{REFERÊNCIAS}

1. ALVES, Barbara Lucia Guimarães. Árvores caídas em São Paulo são transformadas em bancos públicos. São Paulo, 2016. Disponível em:

http://barbarapaisagismoemeioambiente.blogspot.co m/2016/03/arvores-x-mobiliario-urbano.html. Acesso em: 04 set. 2020.

2. BERTRAND, Marion. Le porte manteau arbre ajoute une touche déco à votre intérieur. 2014. Disponível em: https://archzine.fr/maison/le-porte-manteauarbre-ajoute-une-touche-deco-a-votre-interieur/. Acesso em: 04 set. 2020.

3. CICLO VIVO. Design. Brasil, 2020. Disponível em: https://ciclovivo.com.br/inovacao/tecnologia/design. Acesso em: 04 set. 2020.

4. GUIDE ASTUCES. Corbeille décorative en feuilles d'automne, 2015. Disponível em: https://www.guideastuces.com/A12637-Corbeilledecorative-en-feuilles-d-automne. Acesso em: 04 set. 2020. 